\title{
Immersive 3D Experience of Osmosis Improves Learning Outcomes of First-Year Cell Biology Students
}

\section{Nicole B. Reinke, ${ }^{\dagger *}$ Mary Kynn, ${ }^{*}$ and Ann L. Parkinson ${ }^{\dagger}$}

'School of Health and Sports Sciences, University of the Sunshine Coast, Maroochydore Dc, QLD 4558, Australia; and IInstitute of Applied Health Sciences, University of Aberdeen, Aberdeen AB24 3FX, United Kingdom

\begin{abstract}
Abstract biological processes that occur at the submicroscopic level, such as osmosis and diffusion, are inherently difficult for many students to conceptualize when traditional learning and teaching methods are used. This study introduced an immersive $320^{\circ}$ three-dimensional (3D) experience of osmosis in which students became engaged with the cellular environment in a Cave Automatic Virtual Environment. The aims of this study were: 1) to explore whether a textbook diagram of osmosis recreated as an immersive 3D learning experience would be a meaningful tutorial activity for first-year cell biology students at a regional Australian university; and 2) to gather preliminary evidence of the utility of the tutorial by examining student performance data. The experience was perceived by students to be fun, useful, and educational. Performance of all students improved on a multiple-choice exam question, with the percentage of students choosing the osmosis distractor answer decreasing from 26 to 15\% $(p<0.001)$. Those students with moderate to high base-level knowledge also performed better on short-answer questions about the cell membrane and osmosis $(10-14 \%$ better, depending on base-level knowledge, $p<$ 0.001 ). We give recommendations for future studies to investigate using immersive visualization in science teaching.
\end{abstract}

\section{INTRODUCTION}

Understanding how molecules move across the cell membrane is a crucial concept in biology and is one that students need to master to acquire broader and more advanced concepts (Sanger et al., 2001; Lankford and Friedrichsen, 2012; Sung et al., 2017). Knowledge of diffusion and osmosis is required to understand normal and abnormal cellular functions, as well as life processes, such as water movement into the roots of a plant; photosynthesis; cellular respiration; and the swelling of brain cells in cerebral edema. Due to the ubiquity of these processes, most scientists have a solid understanding of osmosis and diffusion; however, learning about these concepts in school or at university is challenging (Johnstone and Mahmoud, 1980; Zuckerman, 1994; Odom, 1995; Odom and Barrow, 1995, 2007; Odom and Kelly, 2001; Fisher et al., 2011; Hasni et al., 2016; Sung et al., 2017; Reinke et al., 2019).

Many studies have identified misconceptions, or alternative, naïve ideas, of osmosis and diffusion held by novice science students. Common misconceptions about osmosis and diffusion include the beliefs that molecules move because they are seeking isolation (anthropomorphizing), molecules only move until isotonicity is reached and then stop moving, and osmosis occurs at a constant rate (Zuckerman, 1994; Odom and Kelly, 2001; Fisher et al., 2011; Artun and Coştu, 2013; Reinke et al., 2019). Despite many years of research into why students have developed these misunderstandings, and onging attempts to dispell them, these misunderstandings have persisted (Marek et al., 1994; Odom, 1995; Odom and Barrow, 1995;
Erika Offerdahl, Monitoring Editor Submitted Nov 25, 2019; Revised Oct 14, 2020; Accepted Oct 21, 2020

CBE Life Sci Educ March 1, 2021 20:ar1

DOI:10.1187/cbe.19-11-0254

*Address correspondence to: Nicole B. Reinke (nreinke@usc.edu.au).

(c) 2021 N. B. Reinke et al. CBE-Life Sciences Education @ 2021 The American Society for Cell Biology. This article is distributed by The American Society for Cell Biology under license from the author(s). It is available to the public under an Attribution-Noncommercial-Share Alike 3.0 Unported Creative Commons License (http://creativecommons.org/licenses/ by-nc-sa/3.0).

"ASCB $\circledR^{\circ}$ " and "The American Society for Cell Biology $\circledR^{\prime \prime}$ are registered trademarks of The American Society for Cell Biology. 
Odom and Barrow, 2007; Jensen et al., 1996; Sanger et al., 2001; Tekkaya, 2003; Fisher et al., 2011; Kramer and Myers, 2012; Reinke et al., 2019). Kramer and Myers (2012) suggested that the ways in which these concepts are taught can explain why students develop consistent misconceptions.

Learning about osmosis and diffusion often begins with gaining an understanding of the structure of the cell membrane. Jenkinson et al. (2012) stated that "Biology is an inherently visual domain," and as such, being able to see or visualize the component parts of the cell membrane and their interactions, even on a simplistic level, is vital to gaining a deep understanding of the concepts related to transport through the membrane. Concept visualization is difficult for students to achieve when it involves processes that occur at the molecular and submolecular levels (McClean et al., 2005). Cellular structures and molecules and their interactions are often simplified and represented as two-dimensional (2D) images, such as those displayed in textbooks. However, 2D images cannot portray the complex three-dimensional (3D) nature of structures such as the cell membrane (Ferdig et al., 2015). Such portrayals often need to be accompanied by explanation in the form of annotating text or cues such as arrows that show directional movement. This format can impart cognitive load related to the interpretation of the information and often opens itself up to misinterpretation (Hoffler and Leutner, 2007). These static, 2D resources also rely on students' ability to mentally animate the image. Hegarty and Sims (1994) suggest that the animation strategies that are used by learners with a range of spatial abilities are similar, but note that some learners with low spatial ability are less accurate in the mental product that is achieved. It is possible that the use of 3D, dynamic imagery may be more equitable for students with a range of spatial abilities and may lead to greater learning outcomes.

Teachers have used different activities and approaches to teach osmosis and diffusion, such as coin-tossing exercises to show the random processes that are central to the process (Haddad and Baldo, 2010), red onions and decalcified chicken eggs to depict net water movement (Lankford and Friedrichsen, 2012), and dialysis bags and potato slices to show the process on a macro scale (Odom et al., 2017). In addition, with advances in technology, there is increasing use of multimedia simulations and dynamic visualizations to complement the traditional methods used to teach osmosis and diffusion (Rundgren and Tibell, 2009; Odom et al., 2017; Sung et al., 2017). Studies of the use of dynamic visualizations to teach these concepts have reported mixed success. For example, first-year biology students who viewed a computer animation on osmosis and diffusion were more likely to correctly answer questions about the dynamic nature of equilibrium and were less likely to anthropomorphize the "desires" of the molecules to move, when compared with students who did not have access to the animations (Sanger et al., 2001). However, these animations also reinforced students' common misconception that molecules continue to move because they would settle to the bottom of the container if they stopped and failed to support the concept of random motion of molecules (Sanger et al., 2001). Sung et al. (2017) allowed one experimental group of students to view animations of osmosis and diffusion before completing an assessment, and the other group viewed the animation after completing the assessment. Those students who had viewed the animations before performed better on the assessment; however, for the most challenging question on the assessment, there was no difference between the groups. The findings of these studies suggest that, even when dynamic visualizations are used to help students learn the processes of osmosis and diffusion, the concepts may still be difficult to master. Students who viewed the animations after completing the quiz considered them more helpful and spent more time on revision, demonstrating that there are psychological nuances to consider when implementing interventions for learning challenging concepts (Sung et al., 2017). A review of dynamic versus static visualizations suggests that the added layer of complexity (animation) is likely to be useful where continuous change is an integral part of the topic of study, but learners require more time for comprehension with this added complexity (see review by McElhaney et al., 2015). This should be taken into consideration when designing a 3D dynamic environment to avoid overwhelming learners' cognitive capacities (Paas et al., 2007).

Virtual reality (VR) takes dynamic computer visualizations a step further by immersing the viewer in the simulated environment through stereoscopic 3D glasses or headsets. While seeing movement in 2D may offer some improvements over 2D static images, 3D dynamic animations may be better at depicting biological concepts such as osmosis and diffusion, as viewing these concepts in 3D is more representative of the "real" interactions and movements. A review of studies across research domains that compare stereoscopic (3D) displays with monoscopic (2D) displays found that the 3D displays were helpful in $\sim 60 \%$ of studies (McIntire et al., 2014), with the suggestion that 3D is only inherently useful if the phenomenon of interest actually "uses" the third dimension. In particular, as cells involve inherently dynamic process that are occurring in complex 3D formations, it has been proposed that 3D technology can help to promote visual-spatial literacy and higher-order thinking in biology students (Ferdig et al., 2015) and this is likely to assist students in learning biological concepts. Cali et al. (2015) created a fully immersive 3D environment in a cubic room as a research tool to depict reconstructed images from real nerve cells. Researchers were able to examine the spatial arrangement of cellular components (e.g., glycogen granules) in a way that surpasses the field of view available when using a 2D monitor (Cali et al., 2015). Such 3D immersive and virtual environments are becoming available to be used as educational environments.

Emotions linked to learning can influence students' engagement and academic performance (Kahu et al., 2015). Emotions affect many components of learning, such as attention, memory, motivation, and self-regulation (Pekrun, 2011). In the learning context, positive emotions such as interest and enjoyment are vital foundations of engagement (Kahu et al., 2015). Interest promotes learning, as it emotionally connects students with the curriculum (Kahu et al., 2015), and also increases exploration and information-seeking behaviors (Krapp, 1999). In addition, interest has been reported to be positively correlated with time and effort dedicated to study (Schiefele, 1991) and, likewise, linked with academic performance (Rawson et al., 2017). Interaction with a 3D visualization on osmosis that evokes a positive emotional experience may lead to improved learning outcomes of this important concept.

In late 2015, the University of the Sunshine Coast, Queensland, Australia opened an innovative immersive 
TABLE 1. Demographic characteristics of students completing LFS100 Cell Biology 2016-2018

\begin{tabular}{|c|c|c|c|c|}
\hline LFS100 & $2016^{\text {a }}$ (Baseline) $n(\%)$ & 2017 (Intervention) $n(\%)$ & 2018 (Intervention) $n(\%)$ & Sig $^{\mathrm{b}}$ \\
\hline Gender & & & & 0.623 \\
\hline Female & $316(65.3)$ & $303(63.0)$ & $342(65.8)$ & \\
\hline Age group & & & & 0.143 \\
\hline$<=20$ & $318(65.7)$ & $290(60.3)$ & $340(65.4)$ & \\
\hline$>20$ & $166(34.3)$ & $191(39.7)$ & $180(34.6)$ & \\
\hline Domestic & $460(95.0)$ & $462(96.0)$ & $505(97.1)$ & \\
\hline International & $24(5.0)$ & $19(4.0)$ & 15 (2.9) & \\
\hline Enrollment type & & & & 0.974 \\
\hline New & $339(70.0)$ & $338(70.3)$ & $362(69.6)$ & \\
\hline Continuing & $145(30.0)$ & $143(29.7)$ & $158(30.4)$ & \\
\hline Participants & $364(75.4)$ & 403 (83.8) & 449 (86.3) & 0.000 \\
\hline
\end{tabular}

aReported in Reinke et al. (2019).

${ }^{\mathrm{b}} \mathrm{Chi}$-squared test of independence.

simulation space specifically for teaching called the Cave Automatic Virtual Environment (CAVE2; Febretti et al., 2013). The CAVE2 provides a $320^{\circ}$, 3D immersive experience in which students do not just view a video or animation but also become engaged with, and part of, the environment. This innovative learning and teaching space provided a unique opportunity to develop and evaluate pedagogy in the area of 3D visualizations in a group immersive setting. The first aim of this preliminary study was to explore whether a textbook diagram of osmosis recreated as an immersive 3D learning experience in the CAVE2 facility would be a meaningful tutorial activity for first-year cell biology students at a regional Australian university. A second aim was to gather preliminary evidence of the utility of the tutorial by examining student performance data.

\section{METHOD}

\section{Participants}

All students enrolled in the first-year course LFS100 Cell Biology during 2016, 2017, and 2018 at the University of the Sunshine Coast were invited to participate in this research study. LFS100 is a required course in 18 degree programs and is used as an elective in other programs from across the university. None of the degree programs have a specific requirement for prior high school chemistry or physics, and these data are not routinely collected. Student characteristics were similar across the 3 years of the study, with a total sample size of 1216 participants (Table 1). Approximately two-thirds were female, two-thirds were under 21 years old, and two-thirds were firstyear students. The majority of students were domestic (i.e., did not require an international visa), and nearly half were the first in their family to attend university. Participation was higher during the intervention years, and this is likely due to the timing in semester, with the initial diagnostic test being given a week earlier in 2017 and 2018. At the time of administration of the conceptual assessment, students were not aware that the following tutorial would include a CAVE2 experience, and so this is unlikely to have influenced participation in the study.

\section{Subject Format}

The regular curriculum about osmosis and diffusion consists of a 2-hour lecture, a 2-hour tutorial class, and a 2-hour laboratory class. The cell membrane structure and function in eukaryotic cells is described in the lecture. In the associated tutorial class, students undertake a modeling exercise in which they manipulate beads to represent molecules inside and outside a cell and participate in a discussion about cell membrane function with their tutor. The laboratory class directs students through a series of experiments using onion cells placed into sugar solutions with increasing solute concentrations. Students view the effects of osmosis as turgid (swollen) or plasmolyzed (shrunken) cells using a microscope.

The intervention in 2017 and 2018 was the addition of an immersive 3D simulation to the tutorial class, in place of a short module on scientific writing, which was made available to students as an online activity. The simulation was conducted in the CAVE2 consisting of 84 3D-enabled flat-screen monitors arranged in a $320^{\circ}$ circle (Figure $1 \mathrm{~A}$ ). The system can display flat $2 \mathrm{D}$ content such as extra-wide PowerPoint presentations (1422.4 $\mathrm{mm}$ by $201.6 \mathrm{~mm}$ ) and can also run 3D environments through the gaming engine, Unity3D. In this scenario, viewers wear passive polarized 3D glasses. The simulation created for LFS100 Cell Biology included a 3D model of an animal cell that was created to look similar to the flat representation in the textbook (Urry et al., 2018) and a close-up view of the cell membrane, including individual moving phospholipids, an aquaporin, and representative molecules such as water and potassium ions (Figure 1C). A rendered 3D 360 video of the environment is available publicly on YouTube (https://youtu .be/8UYQ7pPRvF4) and can be viewed in $2 \mathrm{D}$ on any device or 


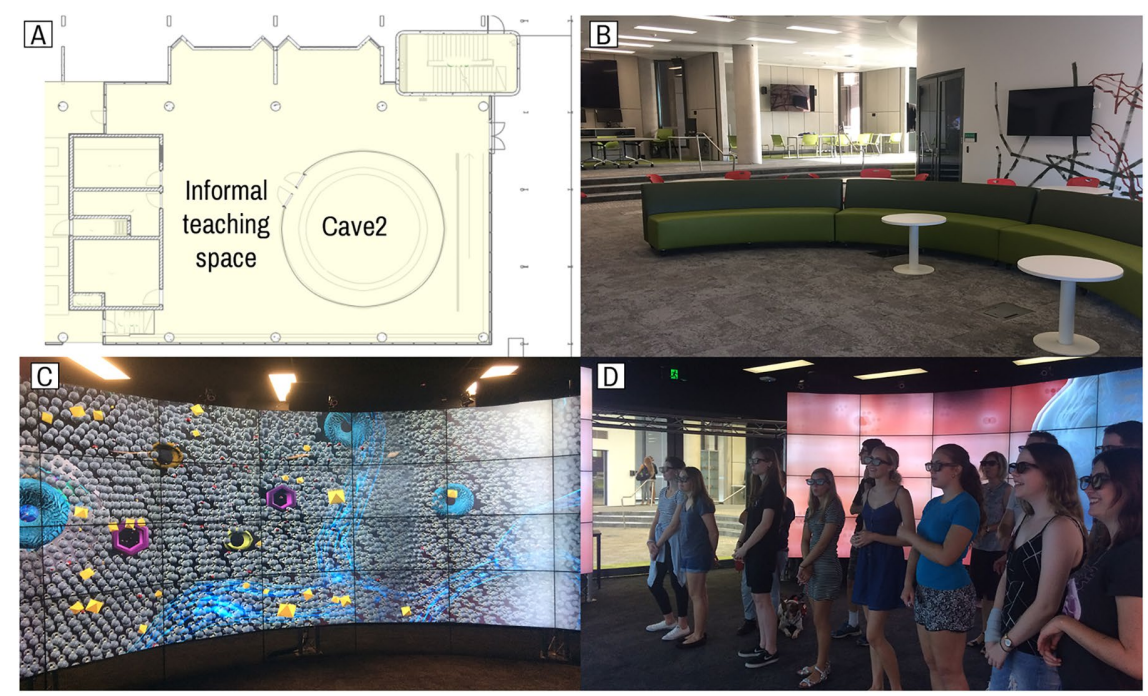

FIGURE 1. (A) floorplan of learning space, including the CAVE2; (B) photograph of the learning space outside the CAVE2; (C) part of the osmosis simulation showing parts of the cell membrane including the phospholipids, protein channels, and representative solutes; (D) tutorial group inside the CAVE2 discussing the simulation.

process of osmosis and the net movement of water into the cell. The overall experience was timed to 6 minutes, as there could be up to three concurrent tutorials that were rotated through the intervention as a part of the regularly scheduled activities.

\section{Instruments and Measures}

Students' scientific understanding of osmosis and diffusion was evaluated using the Osmosis and Diffusion Conceptual Assessment (ODCA; Fisher et al., 2011). The ODCA consists of 18 multiple-choice questions organized into pairs. The first question of each pair asks about what happens within a certain context, and the second question asks about why the event or process happened (Fisher et al, 2011). The ODCA was validated on 408 American university students (Fisher et al., 2011), and two of these questions were modified to be relevant to the regional Australian context (Reinke et al., 2019). Students in all years of the study (2016-2018) com-

in 3D on a VR-compatible device (e.g., a mobile phone with VR glasses). The simulation was a deliberately simplified version of the complex system of animal cells so that the students could relate what they were seeing to the lecture content and $2 \mathrm{D}$ diagrams. It did not include all solutes or interactions between solutes, only a representative solute (potassium) to demonstrate a concentration gradient. However, it was considered imperative that the simulation be dynamic, with molecules always moving and phospholipids "jiggling" to convey to students the key aspects of the fluid nature of the cell membrane and transport across the cell membrane.

The CAVE2 facility can accommodate small groups of up to 15 people. Therefore, the lesson plan required each tutorial class (up to 24 students) to be split into smaller groups of $\sim 12$ students. Students who were not active in the CAVE were occupied watching a simple $2 \mathrm{D}$ video covering concepts on cell membrane structure and function that re-emphasized theory content delivered in the lecture. This video was freely available as an online activity in previous years.

\section{CAVE2 Experience}

The CAVE2 experience involved a tutor taking the students through the $3 \mathrm{D}$ visualization in a semiscripted discussion. Starting with the outside of the cell, the tutor pointed out different features of the cell, representative molecules, and the location of the aquaporins. The visualization would slowly build by adding in the moving phospholipids, followed by the water $\left(\mathrm{H}_{2} \mathrm{O}\right)$ molecules, then a representative solute (potassium ions; $\mathrm{K}^{+}$). Students were asked to note the relative concentrations of the $\mathrm{K}^{+}$and $\mathrm{H}_{2} \mathrm{O}$. Both the $\mathrm{K}^{+}$and the $\mathrm{H}_{2} \mathrm{O}$ were moving, and students could also see the $\mathrm{H}_{2} \mathrm{O}$ moving through the aquaporins into the cell. The tutor "drove" through an aquaporin into the cell. Once inside the cell, the tutor again asked the students to comment on the relative concentrations of $\mathrm{K}^{+}$and $\mathrm{H}_{2} \mathrm{O}$ compared with the outside. This then prompted discussion of the pleted a paper version of the ODCA under examination conditions after the relevant lecture on membrane transport to establish a baseline level of understanding. This baseline knowledge was used as a control variable to capture the differences between students arising from different levels of prior science study, different programs of enrollment, and demographic characteristics, as many of these variables are confounded. For example, the nutrition program attracts a largely female cohort with a high proportion of adult learners and no high school chemistry or physics.

The subjective experience of the CAVE2 immersive visualization for students in 2017 and 2018 was collected through a short exit survey that had been developed by the authors and reviewed by four tutors who had recently taught the course and had tested the 3D experience while in development. Students were asked to select descriptors for their experience of the simulation (positive, exciting, fun, interesting, boring, negative, disorienting, or nerve-racking). Five-point Likert-scale questions requested information about the students' perceptions of the educational value of the simulation. There were three openended prompts asking 1) "If your experience in the CAVE assisted you in your understanding of the osmosis concept, please describe how you think it helped"; 2) "Please make any comments about your experience today in the CAVE2"; and 3) "Please describe any changes that could be made to make this experience more effective.."

The final exam for the course was held at approximately 10 weeks postintervention (including study breaks) and contained an identical multiple-choice question and a short-answer question across all 3 years for a postintervention comparison. The multiple-choice question tested basic foundational knowledge of the concept by asking: "The net movement of molecules from an area of lower concentration to an area of higher concentration is best described by which of the following: (Diffusion/Active transport/Osmosis/Facilitated diffusion)." 
This question was set at the "remember" level of Bloom's taxonomy (Bloom, 1984) and was constructed so that the topic of the intervention was a distractor to reduce any bias created by the small amount of extra time on task and simple word recognition. The short-answer question required more in-depth understanding at the "application" level of Bloom's taxonomy (Bloom, 1984). It had three parts: 1) Describe (or illustrate with a labeled diagram) the general structure of the plasma membrane in a eukaryotic cell. 2) You weigh a piece of potato tissue, then place it into deionized water $\left(\mathrm{H}_{2} \mathrm{O}_{\mathrm{d}}\right)$. After $20 \mathrm{~min}-$ utes of immersion, the net weight of the potato increased. Explain the process that caused the increase in potato tissue weight. 3) You weigh a piece of potato tissue, then place it into 1.0 M sucrose solution. After 20 minutes of immersion, the net weight of the potato decreased. Explain the process that caused the decrease in potato tissue weight. The multiple-choice section of the exam was automatically scanned and marked by a computer. The short-answer question was marked according to a specific marking guide by experienced tutors, consistent across all years of the study, with a sample of exam scripts double marked by the course coordinator at the start of the marking period, with feedback given to tutors where necessary to ensure consistency.

The ODCA was administered in week 5 in 2016 and in week 4 in both 2017 and 2018. The CAVE2 experience was held in week 5 in 2017 and 2018 (there was no CAVE2 experience in 2016). The exam was held at the end of the 13-week semester in the usual exam period each year. Consent was given by students when they completed the ODCA, and these data were later matched with exam information by an independent research assistant not teaching in the course.

\section{Data Analysis and Ethical Considerations}

Cohort demographic characteristics (gender, age, citizenship, enrollment type, and first in family to attend university) were obtained from the university's central database organization, and a chi-squared test of independence was used to test for differences between cohorts (Table 1). For the survey data, agreement with closed questions was described with percentages. Responses to open-ended questions were reviewed for major themes by all authors (N.R., M.K., A.P.) and then coded independently by the first two authors (N.R., M.K.). There was a high level of interrater agreement between the first two authors on major themes with Cohen's $\kappa=0.987(p<0.001)$; any discrepancies were resolved by the third author (A.P.) through discussion. Student comments were chosen that most clearly articulated and represented the major themes. The final exam was marked according to the regular marking protocol described earlier. The proportions of students who chose the distractor option of "osmosis" in the multiple-choice question in baseline and intervention years was compared using Chi-squared tests of independence, and a logistic regression was used to test whether this was moderated by baseline understanding on the ODCA (fail/pass/credit/distinction/ high distinction). For the short-answer question, an independent $t$ test was used to test for an overall difference between baseline and intervention groups, and a two-way analysis of variance (ANOVA) with interaction was used to test whether the short-answer score was moderated by baseline understanding and whether there was any interaction between the receiving the intervention (yes/no) and baseline understanding on the ODCA (fail/pass/credit/distinction/high distinction). IBM SPSS v. 24 was used for all analyses. This research project was approved by the Human Research Ethics Committee at USC (approval no. A16806).

\section{RESULTS}

There was no difference in baseline understanding of osmosis in years 2016-2018 ( $F=2.3$; $p=0.104)$. The overall mean score was $64.9 \%$ (95\% confidence interval [CI]: 63.8 to 66.0). ODCA results for 2016 and 2017 are described in more detail in an earlier study (Reinke et al., 2019). As there were no significant differences in demographic characteristics or baseline understanding, the two intervention years (2017 and 2018) were pooled for the main analysis.

\section{Student Experience Survey}

Overall, 94\% of students who agreed to participate returned CAVE experience surveys ( $n=392$ in 2017, and $n=408$ in $2018)$, which were pooled for analysis $(n=800)$. Nearly all students (97\%) agreed or strongly agreed that the experience helped them visualize how water molecules move into and out of a cell. Most students agreed that they would describe the experience as positive (89\%) and interesting (92\%; Figure 2). There were very few negative responses, and only $8 \%$ of students reported that the $3 \mathrm{D}$ environment was disorienting. One student ticked every single descriptor, both positive and negative, perhaps due to excitement. Over $95 \%$ of students agreed or strongly agreed that the experience promoted their understanding of the osmosis concept $(\mathrm{M}=4.4$, $\mathrm{SD}=0.622$ ), and $98.6 \%$ of students agreed or strongly agreed that the experience helped them visualize the cell membrane and how water moves in and out of the cell $(\mathrm{M}=4.6, \mathrm{SD}=$ 0.526).

In response to the first open-ended prompt, which asked students to explain how the experience assisted understanding (if they had agreed it did), 94\% of students wrote a comment ( $n=$ 751); however, the majority of these (69\%) simply rephrased that they "could see it" or "it was visual." Other comments included that it was immersive, 3D, close up, better than the textbook, or that they liked the teacher-student interaction.

In response to the prompt "Please make any comments about your experience today in the CAVE2," 74\% of students left comments $(n=590)$. Most of the comments (51\%) reiterated that the experience was fun/exciting/awesome. Representative comments include:

"Interesting and a good way, to understand through 'being' in the cell itself rather than watching a normal video."

"Very exciting and assisted my understanding of osmosis."

Positive responses about the educational experiences were made in $28 \%$ of the comments:

\footnotetext{
"Made my understanding of it much better as I felt like I was actually in it."
}

"Very educating to see how the molecules moved through the cell, feel privileged to have experienced this." 


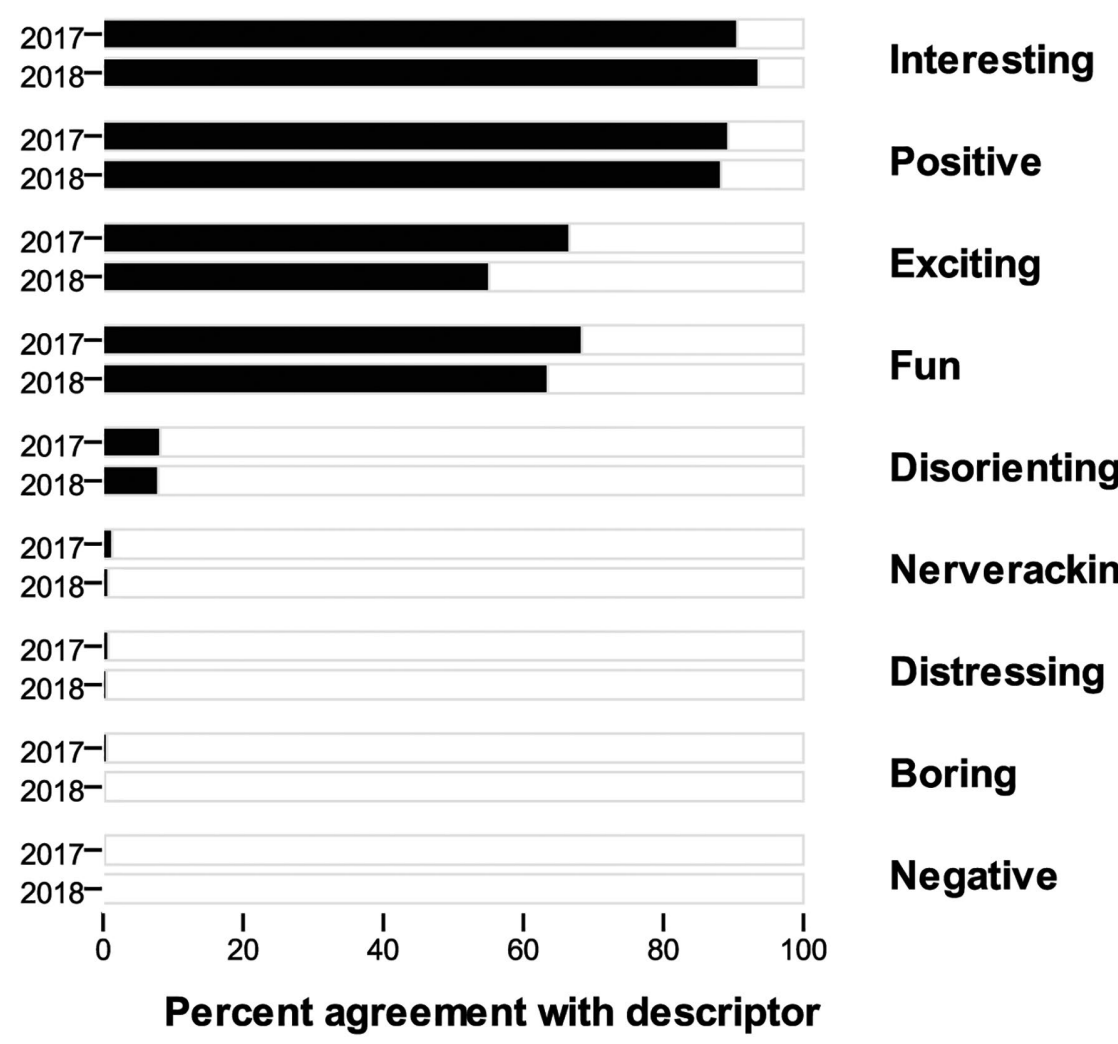

FIGURE 2. Percentage of students agreeing with each descriptor of the intervention (CAVE2) experience in 2017 and 2018.

\begin{abstract}
"How the phospholipids move was amazing (always moving)."
\end{abstract}

Approximately $38 \%$ of comments reflected that it was interesting, educational, or a good learning experience. The remaining $11 \%$ of comments offered a variety of suggestions around timing and classes being offered. The major theme of these comments was a request for additional learning opportunities in the CAVE2 facility.

"It was very interesting. I would like to see more examples of other processes in the body"

"It was fantastic. I would love to see more complex processes being put [brought] to life in the CAVE2!"

\section{"Should do it MORE!!!!"}

The final question asked students to describe any changes they would make to the experience. More than half (55\%) made no comment or explicitly wrote "nothing" or "perfect as is." Thirty percent asked for more time in the CAVE2, more sessions, and more visualizations.

"I wish it was longer"

"More classes in the CAVE so we get more of a visual perspective."
The remaining comments were a variety of suggestions, many useful, about minor changes that could be made, for example changing the audio track or adding labels to the cellular structures.

\section{Exam Results}

There were two specific questions about osmosis and diffusion on the final exam for the subject: one short-answer question and one multiple-choice question. The same questions were used across all years of the study. The multiple-choice question was focused on the topic of diffusion, with "osmosis" included as a distractor answer option. Students who received the CAVE2 intervention were less likely to choose this distractor $\left(\chi^{2}=21.2, p<0.001\right)$, with the proportion of students choosing this distractor decreasing from $26 \%$ in the baseline year to $15 \%$ in the intervention years. To investigate which students were most likely to benefit from the intervention, we grouped students by their grade on the ODCA, based on the percentage of questions answered correctly: 0-49\%, Fail; 50-64\%, Pass; 65-74\%, Credit; 75-84\%, Distinction; and 85-100\%, High Distinction. There was no significant interaction between ODCA grade and year on choosing the "osmosis" distractor option, which suggests that the intervention was beneficial to students with all levels of knowledge (Figure 3).

The short-answer question on the final exam asked students to illustrate and describe the structure of the cell membrane and to explain the net direction of osmosis when potato tissue was placed in either a water or a sucrose solution. The maximum score for this question was 5 points. There was a small but significant difference between the groups, with the students who received the CAVE2 intervention scoring slightly higher on average $(t=2.5, p=0.014)$. Grouping students based on their ODCA grade and using a multivariate analysis revealed that there was no difference on exam short-answer question performance between control and intervention groups for students who achieved Fail or Pass on the ODCA (Figure 4). However, there appeared to be a change in performance for students achieving a grade of Credit or higher. On average, the difference was 0.5 of a mark higher for Credit students and 0.7 mark higher for Distinction and High Distinction students who received the intervention; these are improvements of $10 \%$ and $14 \%$, respectively. This interaction between the ODCA grade and intervention was statistically significant in an ANOVA including the intervention $(F=12.5, p<0.001)$, diagnostic grade $(F=52.5$, $p<0.001)$, and interaction term $(F=3.2, p=0.012)$ as predictors.

\section{DISCUSSION}

In this study, a 3D immersive visualization was developed and deployed to assist students to learn about osmosis in a first-year cell biology subject. The results suggest that students found the 


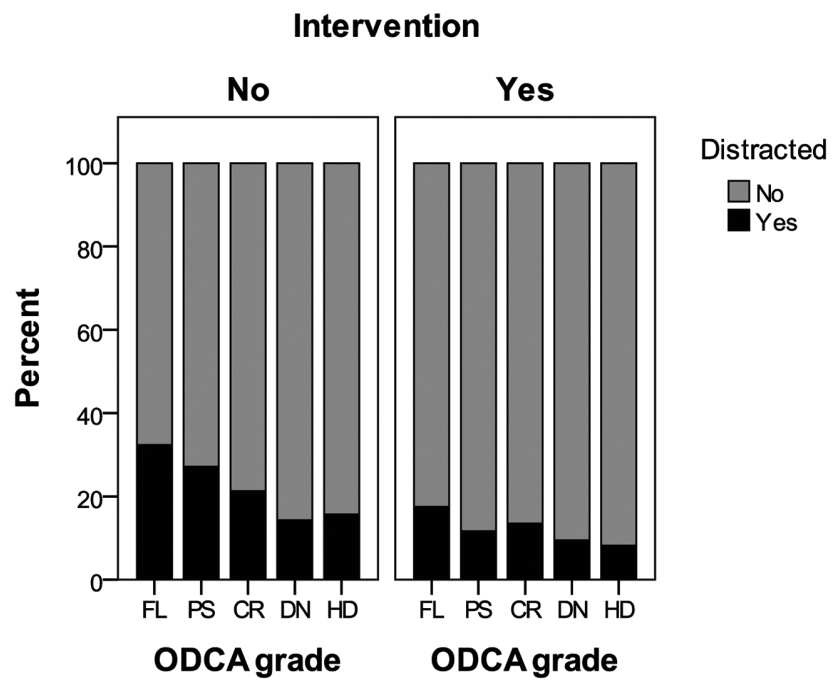

FIGURE 3. The proportion of students selecting "osmosis" as the (incorrect) answer to a multiple-choice exam question on diffusion, split by intervention condition and grade in ODCA as a measure of baseline understanding. FL, fail; PS, pass; CR, credit; DN, distinction; HD, high distinction.

3D immersive experience to be an engaging, fun, and enjoyable activity. Furthermore, there was a small improvement in performance on relevant exam questions by those students who had a moderate to high baseline understanding of the concept before experiencing the immersive visualization.

Our findings demonstrate an important step in the collection of evidence that using 3D immersive environments to teach complex microscopic cellular processes assists learning. However, more broadly, there is limited evidence of the pedagogical benefits of teaching in 3D environments beyond the artifacts

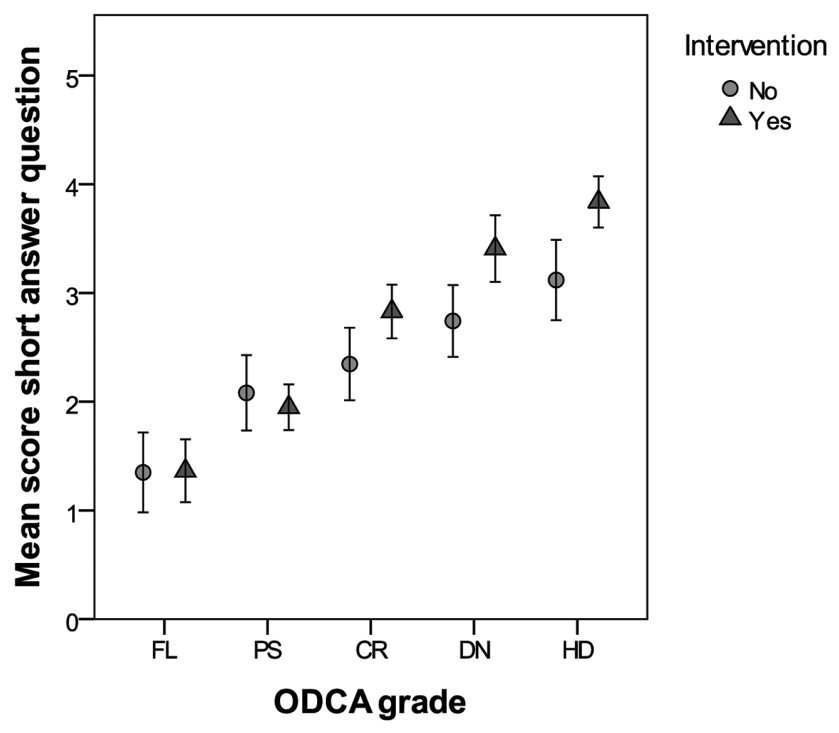

FIGURE 4. Mean scores with $95 \% \mathrm{Cl}$ for a short-answer exam question on the topic of osmosis and the cell membrane, split by intervention condition and grade in ODCA as a measure of baseline understanding. FL, fail; PS, pass; $C R$, credit; $D N$, distinction; $H D$, high distinction. being interesting and enjoyable to engage with (Oloruntegbe and Alam, 2010; Parong and Mayer, 2018). Learning about complex concepts such as osmosis requires students to build mental models of their understanding of the concepts (Schraw et al., 2006). Assisting students to build their own constructs is challenging for various reasons, including the complex nature of the concepts and the need to simultaneously move between molecular, submicroscopic, microscopic, and macroscopic scales (Gilbert, 2008). When learning complex concepts such as osmosis, students often need to engage with multiple representations of the components and processes (Corradi et al., 2014a; McElhaney et al., 2015). In the present study, all three cohorts of students participated in an interactive lecture, had set readings, and had access to a video that contained 2D representations of osmosis and diffusion across cell membranes. The laboratory class directed students through a series of experiments using onion cells placed into sugar solutions with increasing solute concentrations. Students viewed the effects of osmosis (as swollen or shrunken cells) using a microscope. However, what they could not see was the water molecules actually moving both into and out of the cell. It was therefore more challenging for them to link water movement across the cell membrane with the net effect of a change in the cell volume and shape. In the accompanying tutorial class, students undertook a modeling exercise in which they manipulated beads to represent molecules inside and outside the cell. Although this was a "3D" exercise, students tended to focus on placing beads to represent a static end result of osmosis rather than understanding the dynamic movement of the beads occurring via the real process. In addition to these oral, textual, and visual representations, the intervention cohorts also experienced the immersive visualization in the CAVE2. Almost all students acknowledged the educational value of the immersive visualization, agreeing that the experience helped them to "see" the processes, with many focusing on the movement of molecules. This overwhelmingly positive response suggests that the immersive experience added to the other information representations to assist students to build their mental models of the cell membrane, aquaporins, concentration gradients, and movement of water molecules.

Most students in the present study agreed the immersive visualization elicited positive emotions (positive, interesting, fun, and exciting). Similarly, in a study by Parong and Mayer (2018), students rated an immersive VR lesson higher on enjoyment and motivation compared with watching a narrated slideshow. However, based on posttest scores, the slideshow group scored significantly higher than the VR group. When students were prompted to summarize segments of the VR lesson, the scores were comparable with those of the slideshow group (Parong and Mayer, 2018). In the present study, all students learning about osmosis and diffusion engaged with many different representations of the concepts (e.g., aural, 2D lecture slides, textbook text and images, experimental demonstration, and bead activity), and only the intervention cohorts also experienced the immersive visualization. It is possible that, after experiencing the immersive visualization, students were motivated to engage more with the related postvisualization learning tasks, which may then have positive effects on learning and achievement. Emotional events can lead to retention of memories (Tyng et al., 2017), with positive emotional experiences leading to improved learning performance (Chen and Wang, 2011). 
Positive emotions derived from the use of multimedia presentations can increase intrinsic motivation that facilitates learning (Um et al., 2012). It is important to note that, although positive correlations have been found between factors such as interest, exploration, study time, and academic performance, the relationships between emotions and learning are complex (Pekrun, 2011).

Overall, there was a small improvement in students' performance on exam questions about osmosis and the cell membrane. When answering the multiple-choice question, fewer students chose the incorrect "osmosis" option, which reflects an improvement in the level of understanding of the concepts. This improvement was for students with all base-level knowledge about the concepts (as gauged by their performance on the ODCA). The short-answer question on the exam required students to remember and understand information to describe or illustrate the general structure of the cell membrane and also to apply their knowledge toward determining the net direction of osmosis when potato tissue was placed in either water or a sucrose solution. The change in student performance on the short-answer question was small but significant. However, this higher performance was not consistent across all groups of students when viewed according to performance on the ODCA. Those students who answered $65-100 \%$ correct on the ODCA benefited from the intervention, whereas those students who achieved between 0-64\% did not show any improvement with the intervention. Thus, it is possible that the students who had higher prior knowledge of molecules, concentration gradients, and/or membranes, as demonstrated by their higher achievement on the ODCA, may have been better able to expand and deepen their knowledge, aided by visualization of the process, and then apply this knowledge to gain higher marks on the application parts of the exam questions. It is well recognized that understanding concepts in biology often requires background knowledge in chemistry and physics (Michael, 2007; Michael et al., 2009; Modell et al., 2019). For students to understand the movement of water molecules through aquaporins in the cell membrane, they must first grasp the concept of Brownian motion (i.e., continuous and random movements of the molecules) in the context of the cellular environment (Gauthier et al., 2019). Students who had low prior knowledge or understanding of chemistry, as suggested by lower achievement on the ODCA, may have struggled to develop an appropriate mental model of osmosis. However, there was no evidence from the performance data that it harmed the understanding of osmosis for these students. Therefore, given the overwhelmingly positive response to the experience by almost all students, it is possible that the $3 \mathrm{D}$ immersive visualizations will be most successful when targeted at fundamental concepts for lower-achieving students before advancing to more complex biological processes. Depending on the prior knowledge and sophistication of the student cohort, future investigations could also examine the use of immersive visualizations of the concepts that have complex spatial and dynamic arrangements of components.

\section{Limitations}

Students in the intervention years had the benefit of slightly more class time on this concept, as the immersive experience replaced an activity unrelated to the topic (scientific writing module), and it is likely that a greater proportion of students watched a short video on the topic as part of the replacement activities. It is possible that some of the student performance results could be attributed to this additional time on task. However, after the logistics of moving students between buildings during the tutorial, the intervention itself was relatively short (6 minutes).

The survey itself was specifically developed for the study, as there were no existing instruments suitable for adaptation. It was not possible to use a test-retest method of validation, as part of the reaction to the experience was in the novelty. Although there were very consistent responses both years, the value of the open-ended comments was limited, with many students simple reiterating that the experience was fun and visual. Future studies could investigate students' perceptions of their understanding of concepts they experienced using an immersive visualization by embedding the questions of the learning activities into the tutorial so that they reflect on what they have learned from the experience. Furthermore, exploration of emotions before, during, and after the interaction with the 3D visualization could also be explored.

Osmosis was chosen as a fundamental concept that students need to master. However, relative to the overall content of the cell biology subject, it makes up only a small percentage of the assessment. This makes it difficult to quantify the value of the experience, as any changes in grade distributions are likely to be lost in the natural variation between cohorts. Yet small differences were detected on the specific questions in the subject's final exam that were related to the cell membrane and osmosis. Retesting student knowledge using the same conceptual assessment after the CAVE2 experience may have been beneficial for evaluation of the effectiveness of the intervention, but this was not possible due to the already dense curriculum.

Students with low prior knowledge of chemistry are likely to struggle to understand concepts such as osmosis and diffusion. It may have been beneficial to measure the students' prior learning, specifically in chemistry, and to control for it during analysis and evaluation of the effectiveness of the immersive experience. Future studies could therefore provide students with access to remedial chemistry resources and other external representations in the learning activities accompanying the visualization. For example, students could be given opportunities to draw the process of osmosis, take notes, and verbalize the process to their peers (Corradi et al., 2012, 2014b; Wu and Rau, 2018) to help prevent them from developing flawed mental models or to correct misconceptions.

It is possible that one short exposure to the visualization may not have been sufficient to benefit those students with lower baseline understanding (those achieving a Fail or Pass grade on the ODCA). Indeed, many students specifically requested more time in the CAVE2 on the exit surveys. Ayres and Paas (2007) suggest that dynamic visualizations may create a high cognitive workload due to the time-dependent, transient nature of what is seen and the need for students to remember, select, and then integrate the components and events. This high cognitive load might then impede the learning process, such that dynamic visualizations may not be as effective for instruction compared with static visualizations. It is possible that those students with lower baseline understanding did not show the same increase in short-answer question results, as the cognitive load of the 
immersive visualization was too great, compared with the lower cognitive load put on students with higher baseline understanding. However, during the present study, repeat exposure to the immersive visualization was not practical with the size of the cohort and the volume capacity of the CAVE2.

\section{CONCLUSIONS}

An immersive visualization of the cell membrane and osmosis was perceived by students as an advantageous educational tool to be included in the first-year cell biology curriculum. This study showed that an immersive visualization led to a small improvement of student performance data related to the concepts of osmosis and the cell membrane. We recommend that future studies explore students' prior understanding of chemistry and how this is related to the learning of osmosis and similar complex biological concepts. We also recommend further study to explore the exposure to visualizations in assisting learning, students' perceptions of their conceptual understanding and emotions when learning using 3D immersive visualizations, and the use of $3 \mathrm{D}$ visualizations to teach other spatially complex biological concepts.

\section{ACKNOWLEDGMENTS}

This project was funded by a University of the Sunshine Coast Commissioned Learning and Teaching Grant.

\section{REFERENCES}

Artun, H., \& Costu, B. (2013). Effect of the 5E model on prospective teachers conceptual understanding of diffusion and osmosis: A mixed method approach. Journal of Science Education and Technology, 22(1), 1-10. doi: 10.1007/s10956-012-9371-2

Ayres, P., \& Paas, F. (2007). Making instructional animations more effective: A cognitive load approach. Applied Cognitive Psychology, 21(6), 695-700. doi: $10.1002 / a c p .1343$

Bloom, B. S. (1984). Taxonomy of educational objectives. Boston, MA: Allyn and Bacon.

Cali, C., Baghabra, J., Boges, D. J., Holst, G. R., Kreshuk, A., Hamprecht, F. A., ... \& Magistretti, P. J. (2015). Three-dimensional immersive virtual reality for studying cellular compartments in 3D models from EM preparations of neural tissues. Journal of Comparative Neurology, 524(1), 23-38. doi: 10.1002/cne.23852

Chen, C. H., \& Wang, H. P. (2011). Using emotion recognition technology to assess the effects of different multimedia materials on learning emotion and performance. Library \& Information Science Research, 33(3), 244 255. doi: 10.1016/j.lisr.2010.09.010

Corradi, D., Elen, J., \& Clarebout, G. (2012). Understanding and enhancing the use of multiple external representations in chemistry education Journal of Science Education and Technology, 21(6), 780-795. doi: 10.1007/s10956-012-9366-z

Corradi, D., Trinenuh, D. T., Clarebout, G., \& Elen, J. (2014a). How multiple external representations can help or constrain learning in science. Journal of Cognitive Education and Psychology, 13(3), 411-423. doi: 10.1891/1945-8959.13.3.411

Corradi, D. M. J., Elen, J., Schraepen, B., \& Clarebout, G. (2014b). Understanding possibilities and limitations of abstract chemical representations for achieving conceptual understanding. International Journal of Science Education, 36(5), 715-734. doi: 10.1080/09500693.2013.824630

Febretti, A., Nishimoto, A., Thigpen, T., Talandis, J., Long, L., Pirtle, J. D., ... \& Leigh, J. (2013). CAVE2: a next-generation hybrid environment for immersive simulation and information analysis. Engineering Reality of Virtual Reality, 2013. doi: 10.1117/12.2005484

Ferdig, R., Blank, J., Kratcoski, A., \& Clements, R. (2015). Using stereoscopy to teach complex biological concepts. Advances in Physiology Education, 39(3), 205-208.
Fisher, K. M., Williams, K. S., \& Lineback, J. E. (2011). Osmosis and Diffusion Conceptual Assessment. CBE-Life Sciences Education, 10(4), 418-429. doi: 10.1187/cbe.11-04-0038

Gauthier, A., Jantzen, S., McGill, G., \& Jenkinson, J. (2019). Molecular concepts adaptive assessment (MCAA) characterizes undergraduate misconceptions about molecular emergence. CBE-Life Sciences Education, 18(1), ar4. doi: 10.1187/cbe.17-12-0267

Gilbert, J. K. (2008). Visualization: An emergent field of practice and enquiry in science education. In Gilbert, J. K., Reiner, M., \& Nakhleh, M. (Eds.), Visualization: Theory and practice in science education (pp. 3-24). New York: Springer.

Haddad, H., \& Baldo, M. V. C. (2010). Teaching diffusion with a coin. Advances in Physiology Education, 34, 156-157. doi: 10.1152/advan.00009.2010

Hasni, A., Roy, P., \& Dumais, N. (2016). The teaching and learning of diffusion and osmosis: What can we learn from analysis of classroom practices? A case study. EURASIA Journal of Mathematics, Science \& Technology Education, 12(6), 1507-1591. doi: 10.12973/eurasia.2016.1242a

Hegarty, M., \& Sims, V. K. (1994). Individual differences in mental animation during mechanical reasoning. Memory and Cognition, 22(4), 411-430 doi: $10.3758 /$ bf03200867

Hoffler, T. N., \& Leutner, D. (2007). Instructional animation versus static pictures: A meta-analysis. Learning and Instruction, 17(6), 722-738. doi: 10.1016/j.learninstruc.2007.09.013

Jenkinson, J., McGill, G., \& Liu, D. W. C. (2012). Visualizing protein interactions and dynamics: Evolving a visual language for molecular animation CBE-Life Sciences Education, 11(1), 103-110. doi: 10.1187/cbe.11-080071

Jensen, M. S., Wilcox, K. J., Hatch, J. T., \& Somdahl, C. (1996). A computer-assisted instruction unit on diffusion and osmosis with a conceptual change design. Journal of Computers in Mathematics and Science Teaching, 15(1/2), 49-64.

Johnstone, A. H., \& Mahmoud, N. A. (1980). Isolating topics of high perceived difficulty in school biology. Journal of Biological Education, 14(2), 163 166. doi: 10.1080/00219266.1980.10668983

Kahu, E., Stephens, C., Leach, L., \& Zepke, N. (2015). Linking academic emotions and student engagement: Mature-aged distance students' transition to university. Journal of Further and Higher Education, 39(4), 481497. doi: 10.1080/0309877X.2014.895305

Kramer, E. M., \& Myers, D. R. (2012). Five popular misconceptions about osmosis. American Journal of Physics, 80(8), 695-699. doi: 10.1119/ 1.4722325

Krapp, A. (1999). Interest, motivation and learning: An educational-psychological perspective. European Journal of Psychology of Education, 14(1), 23-40. doi: 10.1057/978-1-137-34042-9_3

Lankford, D., \& Friedrichsen, P. (2012). Red onions, elodea, or decalcified chicken eggs? Selecting and sequencing representations for teaching osmosis and diffusion. American Biology Teacher, 74(6), 392-399. doi: 10.1525/abt.2012.74.6.7

Marek, E., Cowan, C., \& Cavallo, A. (1994). Students' misconceptions about diffusion: How can they be eliminated? American Biology Teacher, 56(2), 74-77. doi: 10.2307/4449757

McClean, P., Johnson, C., Rogers, R., Daniels, L., Reber, J., Slator, B. M., ... \& White, A. (2005). Molecular and cellular biology animations: Development and impact on student learning. Cell Biology Education, 4(2), 169179. doi: $10.1187 / \mathrm{cbe} .04-07-0047$

McElhaney, K. W., Chang, H.-Y., Chiu, J. L., \& Linn, M. C. (2015). Evidence for effective uses of dynamic visualisations in science curriculum materials. Studies in Science Education, 51(1), 49-85. doi: 10.1080/03057267 2014.984506

Mclntire, J. P., Havig, P. R., \& Geiselman, E. E. (2014). Stereoscopic 3D displays and human performance: A comprehensive review. Displays, 35(1), $18-$ 26. doi: 10.1016/j.displa.2013.10.004

Michael, J. (2007). What makes physiology hard for students to learn? Results from a faculty survey. Advances in Physiology Education, 31(1), 34-40. doi: 10.1152/advan.00057.2006

Michael, J., Modell, H., McFarland, J., \& Cliff, W. (2009). The "core principles" of physiology: What should students understand? Advances in Physiology Education, 33(1), 10-16. 
Modell, H., Michael, J., \& Wenderoth, M. P. (2019). Helping the learner to learn: The role of uncovering misconceptions. American Biology Teacher, 67(1), 20-26. doi: 10.1662/0002-7685(2005)067[0020:HTLTLT]2.0. $\mathrm{CO} ; 2$

Odom, A. L. (1995). Secondary and college biology students' misconceptions about diffusion and osmosis. American Biology Teacher, 57(7), 409-415. doi: $10.2307 / 4450030$

Odom, A. L., \& Barrow, L. H. (1995). Development and application of a two-tier diagnostic test measuring college biology students' understanding of diffusion and osmosis after a course of instruction. Journal of Research in Science Teaching, 32(1), 45-61. doi: 10.1002/ tea.3660320106

Odom, A. L., \& Barrow, L. H. (2007). High school biology students' knowledge and certainty about diffusion and osmosis concepts. School Science and Mathematics, 107(3), 94-101. doi: 10.1111/j.1949-8594.2007.tb17775.x

Odom, A. L., Barrow, L. H., \& Romine, W. L. (2017). Teaching osmosis to biology students. American Biology Teacher, 79(6), 473-479. doi: 10.1525/ abt.2017.79.6.473

Odom, A. L., \& Kelly, P. V. (2001). Integrating concept mapping and the learning cycle to teach diffusion and osmosis concepts to high school biology students. Science Education, 85(6), 615-635. doi: 10.1002/sce.1029

Oloruntegbe, K. O., \& Alam, G. M. (2010). Evaluation of 3D environments and virtual realities in science teaching and learning: The need to go beyond perception referents. Scientific Research and Essays, 5(9), 948-954. doi: 10.5897/SRE.9000466

Paas, F., Van Gerven, P. W. M., \& Wouters, P. (2007). Instructional efficiency of animation: Effects of interactivity through mental reconstruction of static key frames. Applied Cognitive Psychology, 21(6), 783-793. doi: 10.1002/acp.1349

Parong, J., \& Mayer, R. E. (2018). Learning science in immersive virtual reality. Journal of Educational Psychology, 110(6), 785-797. doi: 10.1037/ edu0000241

Pekrun, R. (2011). Emotions as drivers of learning and cognitive development. In Calvo, R., \& D'Mello, S. (Eds.), New perspectives on affect and learning technologies. Explorations in the learning sciences, instructional systems and performance technologies (pp. 22-39). New York: Springer.

Rawson, K., Stahovich, T. F., \& Mayer, R. E. (2017). Homework and achievement: Using smartpen technology to find the connection. Journal of Educational Psychology, 109(2), 208-219. doi: 10.1037/edu0000130

Reinke, N. B., Kynn, M., \& Parkinson, A. L. (2019). Conceptual understanding of osmosis and diffusion by Australian first-year biology students.
International Journal of Innovation in Science and Mathematics Education, 27(9), 17-33.

Rundgren, C.-J., \& Tibell, L. E. (2009). Critical features of visualisations of transport through the cell membrane-an empirical study of upper secondary and tertiary students' meaning-making of a still image and an animation. International Journal of Science and Mathematics Education, 8(2), 223-246. doi: 10.1007/s10763-009-9171-1

Sanger, M. J., Brecheisen, D. M., \& Hynek, B. M. (2001). Can computer animations affect college biology students' conceptions about diffusion \& osmosis? American Biology Teacher, 63(2), 104-109. doi: 10.1662/0002 7685(2001)063[0104:CCAACB]2.0.CO;2

Schiefele, U. (1991). Interest, learning and motivation. Educational Psychologist, 26(4), 299-323. doi: 10.1207/s15326985ep2603\&4_5

Schraw, G., Crippen, K. J., \& Hartley, K. (2006). Promoting self-regulation in science education: Metacognition as part of a broader perspective on learning. Research in Higher Education, 36(1-2), 111-139. doi: 10.1007/ s11165-005-3917-8

Sung, S. H.-H., Shen, J., Jiang, S., \& Chen, G. (2017). Comparing the effects of dynamic computer visualization on undergraduate students' understanding of osmosis with randomized posttest-only control group design. Research and Practice in Technology Enhanced Learning, 12. doi: 10.1186/s41039-017-0067-3

Tekkaya, C. (2003). Remediating high school students' misconceptions concerning diffusion and osmosis through concept mapping and conceptual change text. Research in Science \& Technological Education, 21(1) 5-16. doi: 10.1080/02635140308340

Tyng, C. M., Amin, H. U., Saad, M. N. M., \& Malik, A. S. (2017). The influences of emotion on learning and memory. Frontiers in Psychology, 8, 1454. doi: 10.3389/fpsyg.2017.01454

Um, E., Plass, J. L., Hayward, E. O., \& Homer, B. D. (2012). Emotional design in multimedia learning. Journal of Educational Psychology, 104(2), 485489. doi: 10.1037/a0026609

Urry, L. A., Meyers, N., Cain, M. L., Wasserman, S. A., Minorsky, P. V., \& Reece, J. B. (2018). Campbell Biology: Australian and New Zealand version. Melbourne, VIC: Pearson Australia.

Wu, S. P. W., \& Rau, M. A. (2018). Effectiveness and efficiency of adding drawing prompts to an interactive educational technology when learning with visual representations. Learning and Instruction, 55, 93-104. doi: 10.1016/j.learninstruc.2017.09.010

Zuckerman, J. (1994). Problem solver's conceptions about osmosis. American Biology Teacher, 56(1), 22-25. doi: 10.2307/4449737 